\title{
Prediction and prevention of type 2 diabetes
}

\author{
Konstantinos Makrilakis, Nikolaos Katsilambros
}

First Department of Propaedeutic Medicine of Athens University Medical School and the Diabetologic Center Laiko General Hospital, Athens, Greece

\begin{abstract}
Type 2 diabetes mellitus is one of the most costly and burdensome chronic diseases of our time and a condition that is increasing in epidemic proportions worldwide. Its complications are a significant cause of morbidity and mortality and a tremendous economic burden to the society. Effective prevention programs are therefore urgently needed. Some of the risk factors for the development of type 2 diabetes, such as obesity, physical inactivity and high-fat diet, can potentially be modified. Compelling evidence now exists from well designed randomized studies that the disease can be prevented or delayed in subjects at high risk for its development, i.e. subjects with impaired glucose tolerance (IGT) or impaired fasting glucose (IFG). The interventions studied include lifestyle modifications (with diet and exercise) and drug treatment. Weight loss with lifestyle modification seems to be the most effective way so far, given the fact that it addresses other cardiovascular disease risk factors as well. The big challenge we are facing now is to try to implement these findings in our society or among our high-risk patients, taking into consideration the great difficulties involved in changing lifestyle and in maintaining lifestyle modifications.
\end{abstract}

Key words: type 2 diabetes mellitus, prediction, prevention, lifestyle interventions

\section{INTRODUCTION}

The prevalence of type 2 diabetes mellitus (DM) is increasing and is reaching epidemic proportions worldwide, as the population becomes older and is less active and more obese. According to recent estimates in the United States, approximately 16 million Americans - one in every 14 individuals - have diabetes ${ }^{1}$. Its future burden worldwide is expected to increase dra-

Address correspondence and requests for reprints to: Prof. N. Katsilambros, 1st Department of Propaedeutic Medicine of the Athens University Medical School and the Diabetologic Center, Laiko General Hospital, 17, Ag. Thoma Str, ATHENS 11527, GREECE, Tel: 210-7771197, Fax: 210-7791839, e-mail: laennec@techlink.gr

Received 02-11-02, Revised 13-12-02, Accepted 27-12-02 matically (from around 155 million people with DM in the year 2000 to around 300 million in the year $2025^{2,3}$, more than $75 \%$ of whom will be in the developing countries).

DM is associated with increased long-term morbidity and an increased risk of mortality ${ }^{4}$. Microvascular complications, for example, lead to more than 50,000 lower extremity amputations each year, about 13,000 new cases of end-stage renal disease (ESRD) and about 15,000 to 39,000 new cases of blindness in the USA alone ${ }^{5}$. Cardiovascular disease is only one of the macrovascular complications and the leading cause of death in these people, especially women ${ }^{6}$. The economic burden of treating diabetes and its complications is likewise enormous ${ }^{7,8}$. Effective primary prevention programs for type $2 \mathrm{DM}$ are therefore urgently 
needed to reduce the clinical and economic health burden. It has been estimated, for example, that by delaying the manifestation of type $2 \mathrm{DM}$ by 6 years with systematic treatment at its onset, the lifetime risk of severe diabetic retinopathy would be reduced by $65 \%$.

The microvascular complications of type $2 \mathrm{DM}$ depend on the duration and intensity of hyperglycemia after the overt clinical manifestation of $\mathrm{DM}^{10,11}$. On the other hand,the risk for macrovascular complications seems to start before the clinical appearance of DM, in the pre-diabetic phase (the ticking clock hypothesis) ${ }^{12}$. Clinically manifested DM constitutes a cluster of cardiovascular risk factors ${ }^{13}$ and the actual number of people at risk for the detrimental effects of diabetes (especially on the cardiovascular system) is much higher than estimated.

Type $2 \mathrm{DM}$ is characterized by hyperglycemia, insulin resistance and relative impairment in insulin secretion. Its pathogenesis is poorly understood, but both genetic factors affecting insulin secretion and responsiveness ${ }^{14}$ and environmental factors, such as obesity, physical inactivity and consumption of dietary fat, appear to contribute ${ }^{15}$. Some of these risk factors for the development of type 2 DM (obesity, physical inactivity, high-fat diet) can potentially be modified. In addition, some of the metabolic abnormalities that precede type $2 \mathrm{DM}$, such as insulin resistance or impaired glucose tolerance (IGT) can be improved by lifestyle changes and possibly drug treatment. Primary prevention of type $2 \mathrm{DM}$ can be implemented either through a population strategy, i.e. changing the lifestyle and environmental determinants that are known to be risk factors for diabetes or through a highrisk strategy, i.e. targeting preventive measures only at those specific individuals or groups that are at high risk for the future development of type 2 diabetes. These include those who have close relatives with type 2 DM, have a history of gestational diabetes or are members of specific ethnic groups (e.g. Pima Indians, Polynesian and other Pacific Islanders, etc $)^{16}$. Another important issue in prevention is distinguishing type 2 diabetes from type 1 diabetes. Although type $1 \mathrm{DM}$ is more common in children and adolescents, approximately $30 \%$ of cases present after the age of $35^{17}$. A number of these patients sustain a slow autoimmune destruction of the pancreatic beta-cells and are characterized as suffering from LADA (Latent Autoim- mune Diabetes in Adults). Prevention programs will obviously work differently in these individuals since the risk factors for developing overt DM are different.

\section{PREDICTION OF TYPE 2 DIABETES}

Our ability to predict type $2 \mathrm{DM}$ in the general population is limited. Abnormal glucose metabolism can be documented years before the onset of overt diabetes ${ }^{18}$. In some groups, insulin resistance appears to be the best predictor of future type 2 diabetes ${ }^{19}$, but tests for insulin resistance are not practical in routine clinical practice. Other studies suggest that abnormalities in insulin secretion may precede the development of insulin resistance ${ }^{20}$.

In epidemiological studies, the development of type 2 diabetes has been associated with various risk factors, such as parental history of diabetes, baseline levels of body mass index (BMI), fasting glucose, plasma glucose levels one hour after a 75-g oral glucose load and black race ${ }^{21}$. Actual overweight or weight gain in lean subjects have also been shown to be associated with increased risk for the development of type 2 diabe$\operatorname{tes}^{22}$, as has a history of gestational diabetes in women ${ }^{23}$. Markers of inflammation ${ }^{24}$, irregular menstrual cycles in women ${ }^{25}$, low birth weight ${ }^{26}$ and cigarette smoking ${ }^{27}$ have also been implicated as risk factors. Subjects with impaired glucose tolerance (IGT) have the highest risk for progression to type 2 diabetes $^{28,29}$ and have been the target for preventive strategies in most studies so far. Subjects with impaired fasting glucose (IFG), i.e. fasting plasma glucose $6.1-7.0 \mathrm{mmol} / 1(110-126 \mathrm{mg} /$ $\mathrm{dl}$ ), have also been found to be at increased risk for the future development of type $2 \mathrm{DM}^{29}$.

A brief review of the significance of the aforementioned risk factors for the development of type 2 diabetes follows.

Impaired Glucose Tolerance (IGT) and Impaired Fasting Glucose (IFG): IGT is defined as an intermediate state between overt diabetes and normal subjects during an oral glucose tolerance test (OGTT). Specifically, patients with IGT have a normal fasting blood sugar $(<7.0 \mathrm{mmol} / \mathrm{l}$ or $<126 \mathrm{mg} / \mathrm{dl})$ and a value of 7.8-11.1 mmol/l (140-200 mg/dl) 2 hours after an oral glucose load of $75 \mathrm{~g}^{30}$. The rate of progression from IGT to overt diabetes varies among different populations. In six prospective studies, for example, 
the incidence rates of type $2 \mathrm{DM}$ among patients with IGT ranged from 36 to 87 per 1000 person-years (or $18-43 \%$ in 5 years) $)^{31}$. The rates were higher among the Hispanic, Pima and Nauruan populations than among the whites. Estimates of obesity (BMI, waist/ hip ratio and waist circumference), but not sex or family history of diabetes, were also related to the rate of progression in these studies. The problem with the OGTT is that it is a time-consuming test with a large within-subject coefficient of variation ${ }^{32}$. Furthermore, it is not sufficiently sensitive to detect early metabolic defects. As an example, first-degree relatives of patients with type $2 \mathrm{DM}$ frequently have impairment in non-oxidative glucose metabolism (indicative of insulin resistance) despite a normal OGTT ${ }^{33}$. For this reason, simpler prediction models have been investigated for identifying persons at increased risk for developing type 2 DM. In a recent study, a simple model that included BMI, fasting plasma glucose and fasting serum lipid profile was superior to the 2-hour plasma glucose value after oral glucose for identifying persons at high risk for developing type $2 \mathrm{DM}^{34}$. Specifically, for prediction of 7.5-year incidence of type 2 $\mathrm{DM}$, the receiver-operating characteristic (ROC) curve for a multivariable model involving the abovementioned variables was significantly greater $(\mathrm{p}<0.001)$ than the area under the ROC curve for the 2 -hour glucose value alone ( $84.3 \%$ vs $77.5 \%$ ). IGT represented a single point on the latter curve. Adding the 2-hour glucose measurement to the multivariable model increased the area under its ROC, but only from $84.3 \%$ to $85.7 \% \%^{34}$.

The addition of the measurement of hemoglobin $\mathrm{A}_{1 \mathrm{c}}\left(\mathrm{HbA}_{\mathrm{lc}}\right)$ to the OGGT seems to offer better prediction capabilities for identifying persons at increased risk for the development of type $2 \mathrm{DM}$. $\mathrm{HbA}_{1 \mathrm{c}}$ is an indirect measure of the average blood glucose concentration over the preceding 2 to 3 months $\mathrm{s}^{35}$ and has certain practical advantages over the OGTT: its measurement is not influenced by the time of the day, recent activity levels, metabolic stress or food intake; only minimal patient cooperation is required before and during the test and only a small blood sample is needed $^{36}$. In a prospective study of 381 non-diabetic high-risk Pima Indians, measurement of $\mathrm{HbA}_{1 \mathrm{c}}$ in addition to the OGTT predicted the development of type 2 DM more accurately than the OGTT alone. Specifically, of those subjects with IGT, a significantly greater percentage with elevated $\mathrm{HbA}_{1 \mathrm{c}}$ at baseline developed
DM within 6 years (68\%), compared with those with normal $\mathrm{HbA}_{1 \mathrm{c}}$ at baseline $(28 \%)^{37}$. Despite the potential usefulness of $\mathrm{HbA}_{1 c}$, the International Expert Committee $^{30}$ does not recommend its use for diagnosing DM or for any screening purposes. The OGTT is still the preferred method in routine practice for identifying persons at high risk for type 2 DM (IGT subjects) and the one that has been used in most studies to predict its development.

The risk of conversion to diabetes is equivalent for IGT and IFG, but these two abnormalities overlap only $20-25 \%$. In the Hoorn study, the risk of conversion to diabetes during a 6.5 -year of follow-up period was more than 8 times higher in people with IGT (57.9/ 1000 person-years) or IFG (51.4/1000 person-years) than in people with normoglycemia (7/1000 personyears). The combination of IFG and IGT in a subject yielded an incidence density for the conversion to diabetes more than 16 times the normoglycemic rate $(112.2 / 1000 \text { person-years })^{29}$. This is why the American Diabetes Association has defined "pre-diabetes" as either IGT or IFG, considering these subjects collectively at high risk for development of diabetes and its complications, and recommends efforts to prevent diabetes specifically in these groups ${ }^{38}$.

Fasting plasma pro-insulin concentrations ${ }^{39}$ or a low insulin response during the first 30 minutes of an OGTT $^{20}$ have also been found to predict the development of type $2 \mathrm{DM}$, but these tests are currently not widely used for screening.

In normoglycemic subjects, serum insulin-like growth factor I (IGF-I) concentrations are inversely correlated with the development of glucose intolerance (IGT or diabetes after 4.5 years of follow-up), suggesting that this hormone may play a role in glucose homeostasis, in particular protecting against the development of glucose intolerance ${ }^{40}$. The usefulness of this test in predicting type $2 \mathrm{DM}$ needs to be elucidated in prospective studies.

Obesity and Dietary Patterns: Obesity is generally defined as a body mass index (BMI) $>30 \mathrm{~kg} / \mathrm{m}^{2}$. A BMI value of $25-30 \mathrm{~kg} / \mathrm{m}^{2}$ is defined as overweight, whereas values $18-25 \mathrm{~kg} / \mathrm{m}^{2}$ are considered to reflect normal body weight ${ }^{41}$. Obesity and overweight increase the risk of developing both IGT and type 2 diabetes at all ages ${ }^{42}$. They act, at least in part, by inducing resistance to insulin-mediated peripheral glucose up- 
take, which is a significant component of type $2 \mathrm{DM}^{43}$.

In addition to the degree of obesity, the distribution of excess fat is another important determinant of the risk of insulin resistance and type $2 \mathrm{DM}$. The degree of insulin resistance and the incidence of type 2 DM are highest in those subjects with upper body or abdominal obesity, as manifested by a waist-to-hip circumference ratio $>0.95$ in men and $>0.85$ in wom$\mathrm{en}^{44}$. Subcutaneous truncal fat rather than intraperitoneal fat appears to be of primary importance in this regard ${ }^{45}$. This "male" type obesity is different from the typical "female" type, which primarily affects the gluteal and femoral regions and is not associated with glucose intolerance or cardiovascular diseases. The reason for this difference in risk between the two types of obesity is not known.

Dietary patterns have also been found to be associated with the risk of type $2 \mathrm{DM}$. In a study of over 42,000 male health professionals, a "western" diet (characterized by high consumption of red meat, processed meat, high fat dairy products, sweets and desserts) was associated with an increased risk of diabetes independent of BMI, physical activity, age or family history (RR: 1.6). In contrast, a "prudent" diet (characterized by higher consumption of vegetables, fruit, fish, poultry and whole grains) was associated with a reduced risk (RR: 0.8$)^{46}$. An inverse association between consumption of dairy products and the insulin resistance syndrome has recently been documented in the CARDIA study (Coronary Artery Risk Development in Young Adults) ${ }^{47}$ in overweight but not lean individuals. In this study, overweight adults with the highest consumption of dairy products $(\geq 35$ times per week) had a significantly lower risk of insulin resistance syndrome when compared to those with the lowest dairy consumption $(<10$ times per week) (adjusted OR: 0.28).

Birth weight: There is an inverse association between birth weight and risk for type 2 DM. Specifically, subjects who had low birth weights for gestational age have as adults reduced beta-cell function, insulin resistance ${ }^{48}$ and an increased incidence of type $2 \mathrm{DM}^{26}$. The reason for this is unclear. One speculation is that intrauterine growth retardation leads to inadequate pancreatic development and impaired maturation of one or more components of the insulin action cascade. Another hypothesis is that fetal malnutrition may result in changes in the metabolic handling of nutrients to provide for more efficient utilization, a process that can be imprinted and become permanent. The individual, when exposed to an abundance of calories in postnatal life, develops central obesity and insulin resistance. Phillips et al. presented evidence for this mechanism when they showed that adults who had intrauterine growth retardation have elevated plasma cortisol levels that are correlated with fasting and 2-h plasma glucose, systolic blood pressure, plasma triglycerides and insulin resistance. They suggested that fetal malnutrition alters intrauterine programming of the hypothalamic-pituitary-adrenal axis ${ }^{49}$.

Markers of Inflammation: Inflammation may play a role in the pathogenesis of diabetes, suggesting that markers of inflammation may identify patients at increased risk for developing the disease. In a subset of 188 women from the Women's Health Study, those women who developed type 2 diabetes during a 4-year follow-up period had significantly higher baseline serum concentrations of interleukin-6 (IL-6) and C-reactive protein (CRP) - two markers of inflammation as compared to 362 age-matched normal control women, who did not develop diabetes ${ }^{24}$. The multivariate relative risk was 2.3 for IL-6 and 4.2 for CRP. Similar findings were noted in the Mexico City Diabetes Study $^{50}$, where baseline CRP levels correlated with the development of DM and the metabolic syndrome in women, but not in men.

Irregular menstrual cycles: Women with long intermenstrual cycles appear to be at increased risk for type 2 DM. In the Nurses' Health Study ${ }^{25}$, the relative risk of developing type $2 \mathrm{DM}$ in women with a menstrual cycle length greater than 40 days, as compared to women with a cycle length of 26-31 days, was 2.1. The risk was greater in obese $\left(\mathrm{BMI}>30 \mathrm{~kg} / \mathrm{m}^{2}, \mathrm{RR}\right.$ : 3.9) than in non-obese women - although the increased risk persisted in them as well $\left(\mathrm{BMI}<25 \mathrm{~kg} / \mathrm{m}^{2}\right.$, RR: 1.7). A possible explanation for this observation is that these women may have polycystic ovary syndrome, which is associated with increased risk for type $2 \mathrm{DM}$, independent of BMI.

Cigarette Smoking: Several large prospective studies have raised the possibility that cigarette smoking increases the risk of type $2 \mathrm{DM}^{27,51-55}$. The relative risk of developing diabetes for individuals who smoked more than 20-25 cigarettes per day in these reports ranged from 1.4 to 3.6, compared to non-smokers. The risk appears to be graded, with increasing risk as the 
number of cigarettes smoked per day and pack-year history rises. Estimates from the Physicians' Health Study suggest that in the U.S.A., where approximately $25 \%$ of people smoke, about $10 \%$ of the incidence of type 2 diabetes may be attributable to smoking ${ }^{27}$. While a definite causal association has not been established and the evidence linking cigarette smoking to diabetes is still considered preliminary ${ }^{56}$, the relationship is biologically plausible: smoking increases blood glucose concentration after an oral and intravenous glucose challenge ${ }^{57}$, impairs insulin sensitivity $^{58}$ and has been linked to increased abdominal fat distribution and increased waist-to-hip ratio ${ }^{59}$, which increase glucose intolerance ${ }^{44}$. A direct toxic effect on pancreatic tissue has also been suggested ${ }^{51}$.

Gestational diabetes: Gestational diabetes (GDM) is a predictor of diabetes (mainly type 2) later in life ${ }^{23,60}$. Women with GDM have defects both in insulin secretion and insulin action ${ }^{61}$, the severity of which correlate with the future development of diabetes. Even one year after delivery, the frequency of glucose intolerance (diabetes and IGT) may be between 9-23\%. Important risk factors for the early development of this glucose intolerance are significant weight gain after delivery, diabetes of a first-degree relative and diagnosis of GDM in the early pregnancy with considerably high fasting glucose values ${ }^{62}$. The cumulative incidence of type $2 \mathrm{DM}$ is about $50 \%$ at 5 years after delivery ${ }^{23}$. The risk is closely related to the results of an OGTT performed 4-16 weeks postpartum: specifically, diabetes developed in $12 \%$ of women with a normal OGTT compared to $84 \%$ of women with IGT postpartum ${ }^{23}$.

Family history of diabetes: People with a family history of type 2 diabetes are likewise at increased risk of developing type $2 \mathrm{DM}$ themselves. There is a strong genetic influence on the development of the disease. The lifetime risk for a first-degree relative of a patient with type $2 \mathrm{DM}$ is 5 to 10 times higher than that of age- and weight-matched subjects without a family history of diabetes ${ }^{63}$. Thirty nine percent of patients with type $2 \mathrm{DM}$ have at least one parent with the disease ${ }^{64}$. Direct evidence for a genetic factor comes from identification of mutations in specific genes that result in a type 2 diabetic phenotype. There are several monogenic forms of MODY (Maturity Onset Diabetes in the Young) that have been described, resulting from point mutations in the glucoki- nase gene as well as in transcription factors involved primarily in beta-cell function ${ }^{65}$. Rare syndromes involving diabetes with mitochondrial and somatic gene mutations have also been described ${ }^{66}$. The vast majority of patients with type 2 diabetes, however, have a polygenic disorder with multiple genetic defects and considerable heterogeneity from a genetic perspective $^{14}$. Mutations in a single gene account for only 5\% of cases of type 2 diabetes ${ }^{67}$. Studies of family and ethnic aggregation of the disease have also provided indirect evidence of a genetic cause of type 2 diabetes ${ }^{68}$. The strongest evidence supporting genetic factors in type $2 \mathrm{DM}$ comes from twin studies which have shown almost complete concordance for type $2 \mathrm{DM}$ in monozygotic twins ${ }^{69}$.

\section{PREVENTION OF TYPE 2 DIABETES}

Given the fact that type 2 diabetes is a widespread, devastating disease with significant morbidity and mortality and inflicting an enormous economic burden on society, it is not surprising that studies have been initiated in the last decade to determine the feasibility and benefit of various strategies to prevent or delay its onset. Although, as stated above, there is evidence that many risk factors are independently associated with the development of type $2 \mathrm{DM}$ (such as age, family history, obesity, low birth weight, history of gestational diabetes, cigarette smoking), the majority of studies show that the incidence of type $2 \mathrm{DM}$ is most strongly related to the hyperglycemic states of IGT and IFG. None of the other factors taken singly is as good in discriminating who will progress to diabetes as measuring glucose levels (fasting or postprandial). It should be noted, however, that when taken in the aggregate, these risk factors combined with glucose levels are more predictive of future diabetes than are glucose levels by themselves ${ }^{34}$. Since these two prediabetic states (IFG and IGT) are relatively easily, reliably and safely identified (with a fasting blood glucose measurement and an OGTT), most studies investigating the issue of preventing type $2 \mathrm{DM}$ have concentrated on them. The methods used to accomplish this goal of preventing type 2 diabetes have been either through lifestyle interventions (with diet and/ or exercise) and/or medications.

Lifestyle Interventions: Since obesity and physical inactivity are risk factors for the development of the metabolic syndrome and DM, many studies have 
investigated the role of weight loss through diet and/ or physical activity in their prevention.

When performed on a regular basis, exercise may improve glycemic control and several diabetes-related cardiovascular risk factors, including hypertension and hypertriglyceridemia. The metabolic benefits appear to be partly related to the enhancement of insulin sensitivity ${ }^{70}$. In addition, exercise may be a useful adjunct to diet in producing weight loss. In a prospective study of 5,990 male alumni of the University of Pennsylvania, followed for 14 years (from 1962 to 1976), leisure time physical activity (expressed in kilocalories [kcal] expended per week in walking, stair climbing and sports), was inversely related to the development of type 2 diabetes $^{71}$. The incidence rates declined as energy expenditure increased from $<500$ $\mathrm{kcal}$ to $>3500 \mathrm{kcal}$ per week. For each 500-kcal increment in energy expenditure, the age-adjusted risk of type $2 \mathrm{DM}$ was reduced by $6 \%$. The protective effect of physical activity was strongest in persons at highest risk for type $2 \mathrm{DM}$, defined as those with a high BMI, a history of hypertension or parental history of diabetes.

The benefit of exercise has also been shown in persons with IGT. In a 6-year prospective non-randomized study from Sweden ${ }^{72}$, - the Malmo feasibility study - a program of diet plus regular exercise training was given to 161 men with IGT identified during screening of almost 7,000 men, aged 47-49 years. These 161 men were compared with 56 men with IGT who were not enrolled in the program for various reasons, but had similar baseline characteristics. The men in the intervention group were advised to reduce fat and sugar intake, to increase complex carbohydrate and fiber in the diet, to reduce body weight and to take part in a physical training program. The treated subjects produced a significant weight loss $(2.3-3.7 \%$ vs $0.5-1.7 \%$ in controls), which in most cases was maintained for 5 years. At follow-up 5 years later, glucose tolerance had improved in $76 \%$ of the subjects in the intervention group but had deteriorated in $67 \%$ of those in the control group. Diabetes had developed in $11 \%$ of the subjects in the intervention group vs $29 \%$ of the controls (RR: $0.37, \mathrm{p}<0.003$ ).

In the Chinese Da Qing IGT and Diabetes Study ${ }^{73}$, a total of 577 subjects with IGT were randomized by clinic to either a control group or to one of three active treatment groups: diet only, exercise only, or diet plus exercise. Follow-up evaluation examinations were conducted at 2-year intervals over a 6-year period to identify subjects who developed type $2 \mathrm{DM}$. The cumulative incidence of DM at 6 years was $67.7 \%$ in the control group compared to $43.8 \%$ in the diet group, $41.1 \%$ in the exercise group and $46.0 \%$ in the dietplus-exercise group. These effects persisted after stratification for obesity (BMI $<$ or $\geq 25 \mathrm{~kg} / \mathrm{m}^{2}$ ). In a proportional hazards analysis, adjusted for differences in baseline BMI and fasting glucose, the diet, exercise and diet-plus-exercise interventions were associated with $31 \%(\mathrm{p}<0.03), 46 \%(\mathrm{p}<0.0005)$ and $42 \%$ $(\mathrm{p}<0.005)$ reductions in the risk of developing type 2 DM, respectively.

These two earlier reports (the Malmo feasibility study $^{72}$ and the Chinese study ${ }^{73}$ ), although suggesting that changes in lifestyle through diet and exercise could prevent type 2 diabetes, were criticized for weaknesses in study designs (non-randomization in the Swedish study, randomization by clinics instead of by subjects in the Chinese study), which limited their general relevance. Recently, however, two well-designed, randomized, controlled trials have been reported that strengthen the assumption that lifestyle interventions can effectively prevent type 2 diabetes ${ }^{74,75}$.

In the Finnish study ${ }^{74}, 522$ middle-aged (mean age 55 years), obese (mean BMI $31 \mathrm{~kg} / \mathrm{m}^{2}$ ) subjects with IGT were randomized to receive either brief diet and exercise counseling (control group) or intensive individualized instructions on weight reduction, food intake and guidance on increasing physical activity (intervention group). After an average follow-up of 3.2 years, there was a relative reduction of $58 \%(\mathrm{p}<0.001)$ in the incidence of diabetes in the intervention group compared to the control subjects (Figure 1). The mean weight loss in the intervention group was $3.5 \mathrm{~kg}$ at the end of two years, compared to $0.8 \mathrm{~kg}$ in the control group. A strong correlation was also seen between the ability to stop the progression to diabetes and the degree to which subjects were able to achieve one or more of the following goals: lose weight (goal $>5 \%$ weight reduction), reduce fat intake (goal of $<30 \%$ of calories), reduce saturated fat intake (goal of $<10 \%$ of calories), increase fiber intake (goal of $\geq 15 \mathrm{~g} / 1000$ $\mathrm{kcal}$ ) and exercise (goal of $>30$ minutes/day). No untoward effects of the lifestyle intervention was observed.

In the Diabetes Prevention Program ${ }^{75}$, a total of 


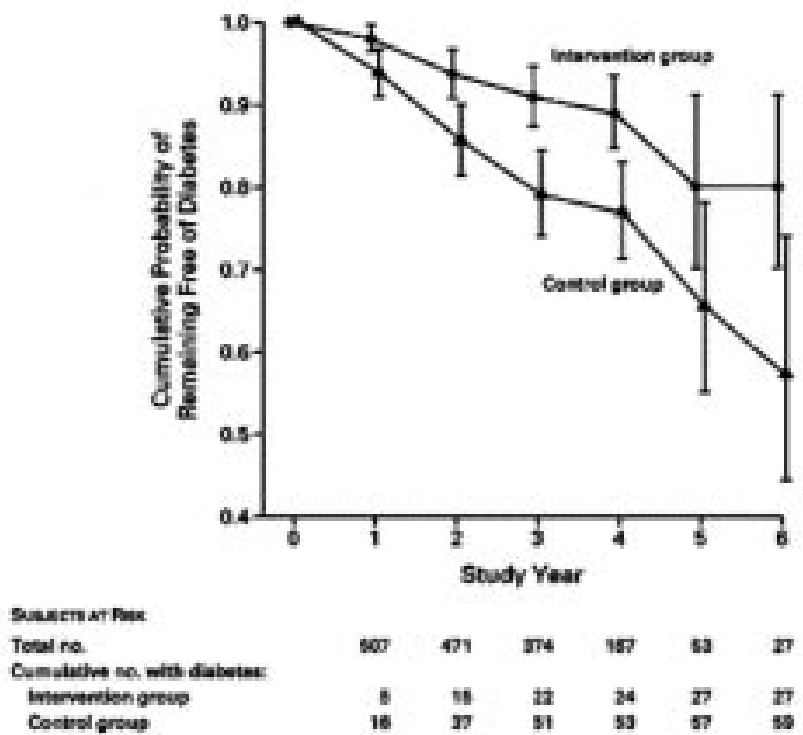

Figure 1. Proportion of subjects without diabetes during the trial. The vertical bars show the $95 \%$ confidence intervals for the cumulative probability of remaining free of diabetes. The relative risk of diabetes for subjects in the intervention group, as compared with those in the control group, was $0.4(\mathrm{p}<0.001$ for the comparison between the groups).

3,234 non-diabetic persons with elevated fasting and post-load glucose concentrations were randomly assigned to placebo, metformin (850 $\mathrm{mg}$ twice daily) or a lifestyle modification program with the goals of at least $7 \%$ weight loss and at least 150 minutes of physical activity per week. A 16-lesson curriculum covering diet, exercise and behavior modification was designed to help the participants of the latter group achieve these goals. The mean age of the participants was 51 years, the mean BMI $34 \mathrm{~kg} / \mathrm{m}^{2}$ and $45 \%$ were members of minority groups. The study was terminated early, after an average follow-up of 2.8 years (range 1.8 to 4.6 years) when it became clear that the results in the diet and exercise group were superior to those in the other groups. There was a $58 \%$ relative reduction in the progression to diabetes in the lifestyle intervention group and a $31 \%$ relative reduction in the progression to diabetes in the metformin group compared with control subjects (Figure 2). The lifestyle intervention was also significantly more effective than metformin (39\% relative reduction) in preventing type 2 diabetes. On average, $50 \%$ of the lifestyle group achieved the goal of $>7 \%$ weight reduction and $74 \%$ maintained at least $150 \mathrm{~min} /$ week of moderately intense activity. The average weight loss

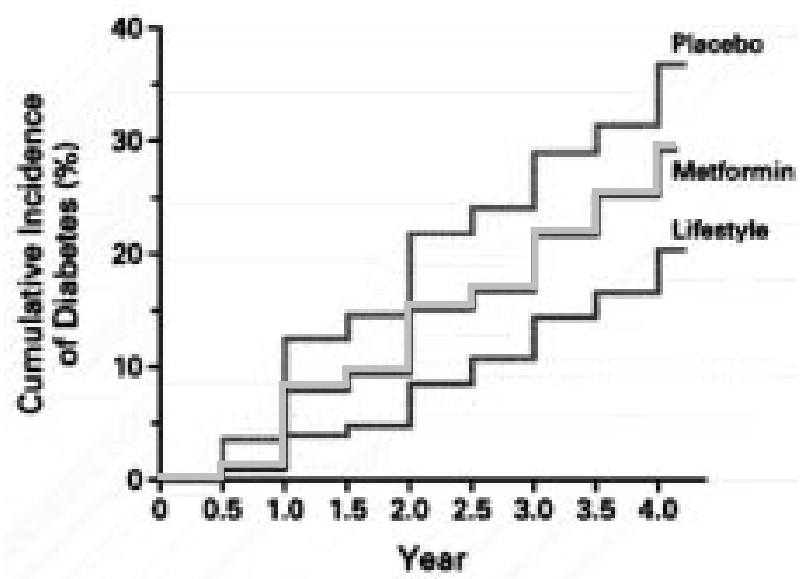

Figure 2. Cumulative incidence of diabetes according to study group. The incidence of diabetes differed significantly among the three groups ( $\mathrm{p}<0.001$ for each comparison).

was $0.1,2.1$ and $5.6 \mathrm{~kg}$ in the placebo, metformin and lifestyle intervention groups, respectively. Lifestyle intervention was effective in men and women, in all age groups and in all ethnic groups. No serious side effects were seen in any groups.

The combined effects of diet and healthy lifestyle were also important for the prevention of type 2 diabetes in women in the Nurses' Health Study, where $91 \%$ of the cases of diabetes could be attributed to obesity, lack of exercise, a poor diet, smoking and alcohol consumption ${ }^{76}$. These findings suggested that many cases of diabetes could be prevented with a healthier lifestyle. A similar positive effect of diet and exercise has been reported in Japanese-American men and women ${ }^{77}$. A beneficial effect of weight loss for the prevention of progression of IGT to overt DM through bariatric surgery has also been observed in 109 morbidly obese patients with IGT ( $>45 \mathrm{~kg}$ excess body weight, mean BMI $48 \mathrm{~kg} / \mathrm{m}^{2}$ ), as compared to $27 \mathrm{sim}$ ilarly obese subjects with IGT (mean BMI $51 \mathrm{~kg} / \mathrm{m}^{2}$ ) who did not undergo surgery. The risk of DM was reduced by more than 30 -fold in the surgery group who lost about $50 \%$ of their excess weight over a period of 5.8 years $^{78}$.

Since many epidemiological studies have shown that cigarette smoking may be associated with increased risk for the development of type 2 diabetes ${ }^{27,51-55}$, studies have been carried out to examine the impact of smoking cessation on preventing diabetes. In a recent prospective study of 7,735 men, aged 40-59 years, fol- 
lowed for an average of 16.8 years, cigarette smoking was found to be associated with increased risk of diabetes, even after adjustment for age, BMI and other potential confounders ${ }^{79}$. The benefit of giving up smoking was only apparent after 5 years of smoking cessation and risk reverted to that of never-smokers only after 20 years. Men who gave up smoking during the first 5 years of follow-up showed significant weight gain and subsequently higher risk of diabetes than continuing smokers, during these first 5 years. The risk of diabetes in those who switched from smoking cigarettes to pipes or cigars remained equal to the risk in continuing cigarette smokers.

Pharmacological Interventions: Due to ethical and socioeconomic considerations, any medicine regarded as a means of preventing type 2 diabetes must have a proven efficacy in influencing at least one of the metabolic abnormalities of pre-diabetes, and - most important - have an excellent safety profile. Various kinds of medications have been studied so far for the prevention of type $2 \mathrm{DM}$. Four of them have proven effective to date.

As stated earlier, metformin was found to reduce the incidence of type 2 diabetes by $31 \%$ compared to placebo, in the Diabetes Prevention Program ${ }^{75}$. Metformin was about half as effective as diet and exercise in delaying the onset of diabetes overall ( $31 \%$ vs $58 \%$ ), but it was virtually ineffective in older individuals $(\geq 60$ years of age) or in those who were less overweight $\left(\mathrm{BMI}<30 \mathrm{~kg} / \mathrm{m}^{2}\right)$. Conversely, metformin was as effective as lifestyle modification in individuals aged 2444 years (44\% risk reduction) or in those with a BMI $\geq 35 \mathrm{~kg} / \mathrm{m}^{2}$ (53\% risk reduction). Thus, the population of people in whom treatment with metformin has equal benefit to that of a lifestyle intervention is only a small subset of those likely to have IGT or IFG. The way metformin exerts its beneficial effects is thought to be through normalization of impaired glucose tolerance in obese subjects ${ }^{80}$, suppression of elevated rates of hepatic glucose production ${ }^{81}$ and probable delay or inhibition of glucose absorption from the gastrointestinal tract ${ }^{82}$. Metformin has also been shown to decrease food consumption and to induce weight loss in obese subjects with type 2 diabetes $^{83}$.

In the STOP-NIDDM trial ${ }^{84}, 1,429$ participants with IGT were randomized in a double-blind fashion to receive either the a-glucosidase inhibitor acarbose (100 mg three times a day) or a placebo. The subjects had a mean age of 54.5 years and a mean BMI of 31 $\mathrm{kg} / \mathrm{m}^{2}$. After a mean follow-up of 3.3 years, a $25 \%$ relative risk reduction in progression to diabetes, based on one OGTT, was observed in the acarbose-treated group compared to the placebo. If the diagnosis was confirmed by a second OGTT, a $36 \%$ relative risk reduction was observed in the acarbose-treated group compared to the placebo group. The effect of acarbose was consistent among all age groups, BMI values and both sexes. The mode of action of acarbose is thought to be through improvement of insulin sensitivity and decrease of post-prandial hyperglycemia, thereby decreasing the stress of hyperglycemia on the beta-cells ${ }^{85}$.

In the Troglitazone In Prevention Of Diabetes (TRIPOD) study ${ }^{86}, 236$ Hispanic women with previous gestational diabetes were randomized to receive either placebo or troglitazone (a thiazolidinedione withdrawn from the market since 1998 because of significant liver toxicity). After a median follow-up of 30 months, the annual incidence of type 2 diabetes in the two groups was $12.1 \%$ and $5.4 \%$, respectively $(\mathrm{p}<0.01)$. Thus, troglitazone was associated with a $56 \%$ relative reduction in progression to diabetes. Of note is the fact that, after a washout period of $>8$ months, the preventive effects of the drug were still observed. The protective effect was associated with the preservation of pancreatic beta-cell function and appeared to be mediated through a reduction in the secretory demands placed on beta-cells by chronic insulin resistance. Thus, it is possible that troglitazone, acting through the nuclear receptors PPAR $\gamma$, may affect the natural history of glucose intolerance and may actually prevent diabetes in some people rather than just delay its onset. Future studies with the other two thiazolidinediones currently on the market (rosiglitazone and pioglitazone) will show if these effects are really class-effects and if these medicines, by improving insulin sensitivity, prove helpful in preventing type 2 diabetes.

In the XENDOS (XENical in the prevention of Diabetes in Obese Subjects) study ${ }^{87}, 3,304$ obese subjects (mean BMI $37.3 \mathrm{~kg} / \mathrm{m}^{2}$ ) $-21 \%$ with IGT at baseline - mean age 43.3 years, were randomly assigned to treatment with the weight loss agent orlistat (120 $\mathrm{mg}$ three times daily) plus lifestyle changes $(800 \mathrm{kcal} /$ day deficit and moderate physical exercise) or placebo and lifestyle changes. People were monitored over 
a period of 4 years for the prevention of type 2 diabetes. Mean weight loss was significantly greater in orlistat than in placebo patients at 1 year and at the end of the 4 years. The hazard ratio analysis showed that at 4 years, orlistat had decreased the risk of type 2 diabetes by $37.3 \%$ compared to placebo. Orlistat treated patients also achieved a significantly greater mean reduction in waist circumference and LDL-cholesterol and greater improvement in systolic and diastolic blood pressures than placebo treated patients.

A surprising finding in the Heart Outcomes Prevention Evaluation (HOPE) trial of patients with cardiovascular disease was that angiotensin-convertingenzyme (ACE) inhibitors may delay or prevent the onset of type 2 diabetes $^{88}$. Among the 5,720 patients in the study who were non-diabetic at randomization, 257 developed diabetes during the 4.5 years of followup. There were significantly fewer cases in the ramipril (the ACE-inhibitor) group than the placebo group (3.6 \% vs 5.4\%; RR: 0.66, p<0.001). A similar benefit was noted with the angiotensin II receptor blocker losartan in hypertensive patients ${ }^{89}$. How inhibition of angiotensin II activity may prevent type 2 diabetes is still unclear. Possible mechanisms include increased insulin sensitivity and increased blood flow to the pancreas $^{90}$.

The use of sulfonylureas in prevention studies of type 2 diabetes is somewhat ambiguous. In two previous randomized studies performed in Bedford ${ }^{91}$ and Malmohus ${ }^{92}$ County in Sweden, there was no discernible effect of tolbutamide therapy on the incidence of type 2 diabetes over a 10-year period. In the latter study ${ }^{92}$, tolbutamide treatment showed a reduction in the incidence of diabetes, but only on 23 subjects with IGT, thus yielding inadequate statistical power and consequently equivocal results. Similarly negative results had been reported earlier with chlorpropamide ${ }^{93}$. Thus, together with the considerable risk for hypoglycemia, sulfonylureas are not considered very good candidates for prevention studies.

\section{CONCLUSIONS}

Type 2 diabetes is a major public health problem and the resultant enormous personal and social costs in terms of complications, patient quality of life and health care system resources are now widely recognised $^{4-8}$. The current system of reactive, acute episode focused disease care, practiced in most (if not all) countries, does not adequately address this public health problem. Without an adequate approach to the prevention of type 2 diabetes, the current type of curative medicine, by simply reducing or delaying mortality without preventing morbidity, is creating the predicted "global burden of type 2 diabetes" 2 . Type 2 diabetes is projected to become an even bigger problem in the developing countries, affecting more middle-aged people in the future. These predictions should lead to prevention strategies aiming at the reduction of risk factors which requires urgent action from national and international public health services. Ideally, this should be part of an integrated program that addresses lifestyle-related disorders. This appears to be the most promising way to prevent some of the consequences of the so-called "coca-colonization", one of them being the emerging global epidemic of type 2 diabetes in the next decades ${ }^{94}$. In addition, in populations at high risk, pharmacological measures to prevent or delay the development of type 2 diabetes may also be useful.

The prevention studies mentioned above, and especially the recent Finnish Diabetes Prevention Study ${ }^{74}$ and the USA Diabetes Prevention Program (DPP) ${ }^{75}$, showed rather conclusively that the natural history of the development of type 2 diabetes can be altered. The most heartening news is that this delay or prevention of type 2 diabetes can be accomplished with a safe, inexpensive therapy, namely lifestyle modification (with the reservation, of course, that exercise-related injuries are not uncommon). The appeal of lifestyle interventions is that, apart from being inexpensive and generally safe, they also reverse the proximal factors associated with diabetes - i.e. overweight, central obesity, physical inactivity, high-fat and high-energy diets. In the process, they also promote health in general (by reducing blood pressure and lipids), empower people, make them less reliant on medicine and improve quality of life. Thus, focusing on lifestyle interventions truly shifts the paradigm from preventing disease to promoting health and well-being ${ }^{95}$.

The flip side to our optimism is that we currently live in a society that is becoming ever more sedentary and obese. Indeed, this is the main reason we have seen such an increase in the incidence of type 2 diabetes. The increased availability of "fast foods", the lack of physical activity in our daily lives, the increase 
in our dependence on the automobile and other unhealthy social developments are taking their toll. Although these recent studies indicate that, if we reverse our current lifestyle trends, we will reduce the burden of diabetes, the truth is that lifestyle changes are for most of us, a difficult challenge. Although both intervention studies mentioned above ${ }^{74,75}$ showed that diabetes could be prevented or delayed with only modest changes in weight and physical activity, considerable effort from well-trained staff was required to achieve these behavioral changes. In the Finnish study ${ }^{74}$, the intervention group had 7 sessions with a nutritionist during the first year and 1 session every three months thereafter. They also received individualized guidance on increasing physical activity. Free membership to an exercise club was also offered. In the DPP ${ }^{75}$, participants in the lifestyle arm met with a case manager 16 times over the first 6 months and monthly thereafter. They made telephone contact at least monthly. Group courses on exercise and weight loss, lasting 4-6 weeks, were offered every 3 months. Two supervised exercise sessions were offered each week. Moreover, anyone having difficulty achieving or maintaining the study's goals on weight loss or exercise were offered incentives, such as exercise tapes or equipment, free enrollment in exercise facilities, free low-calorie foods, more structured eating plans and home visits for encouragement and counseling. Keeping all this in mind and considering the generally modest goals of weight loss (5\% and $7 \%$ in the two studies, respectively), it is certainly discouraging that the substantial levels of effort described above were only partially successful in achieving the desired objectives. In the Finnish study, only $43 \%$ of subjects achieved the weight reduction goal and $36 \%$ increased their physical activity. In the DPP, only $50 \%$ reached the weight loss goal and $74 \%$ reached the exercise goal. In both studies, some weight was regained despite the continuation of intensive strategies. Similar difficulties in maintaining weight loss and physical activity levels have been described in other studies of lifestyle intervention ${ }^{96}$. The real challenge therefore now is not only to change the lifestyle of individuals at risk of developing type 2 diabetes but of the entire society.

Apart from lifestyle modifications, medications were shown in the above mentioned studies to be effective in the prevention of type 2 diabetes. With the exception of troglitazone though in the TRIPOD
Study $^{86}$ (which showed a 56\% risk reduction compared to placebo), the other medicines studied (metformin, acarbose and orlistat) were half as effective as the lifestyle interventions. We do not yet know if the newer thiazolidinediones (pioglitazone and rosiglitazone) will be equally effective as troglitazone, which has been discontinued due to serious hepatic side-effects.

In response to this impressive evidence, the American Diabetes Association's Position Statement on prevention of diabetes ${ }^{38}$ has recommended screening to detect people with IGT or IFG during routine healthcare office visits by people over age 45 years particularly those with a BMI $>25 \mathrm{~kg} / \mathrm{m}^{2}$. These people, collectively referred to as "pre-diabetes", will be given counseling on weight loss as well as instruction on increasing their physical activity. Since all people who develop diabetes go through pre-diabetes (although the length of this phase may vary $)^{97}$, effectively delivering preventive methods to people with prediabetes will ensure that most, if not all, future cases of diabetes are targeted ${ }^{98}$. Using medications to prevent diabetes is not yet recommended in the Position Statement, given the cost, side effects and relative ineffectiveness compared with lifestyle modifications.

Hopefully, newer medications currently in ongoing clinical trials will prove more effective than those studied so far. The combination of nateglinide (a new insulin secretagogue that restores the reduced first phase of insulin release in people with IGT and early diabetes) together with valsartan (an angiotensin II, type 1 , receptor inhibitor) are currently being studied in a large multi-center study of 7,500 people with IGT - the NAVIGATOR study (Nateglinide $\underline{\text { And }}$ Valsartan In impaired Glucose Tolerance Outpatient $\underline{R e}-$ search). Also, the combination of ramipril (an ACE inhibitor) and rosiglitazone (a thiazolidinedione) are being investigated in a 3-year study involving 6,000 subjects with IGT, regarding the prevention of type 2 diabetes (the DREAM Study: Diabetes REduction Approaches with ramipril and rosiglitazone Medications).

Another important issue to be addressed in future studies is whether intervention at the stage of IGT or IFG is a cost-effective way to prevent or delay the complications of diabetes, an issue of greater importance to the patient, family and society than simply the diagnosis and prevention of diabetes itself. 


\section{REFERENCES}

1. Harris MI, Flegal KM, Cowie CC, et al, 1998 Prevalence of diabetes, impaired fasting glucose, and impaired glucose tolerance in U.S. adults: the Third National Health and Nutrition Examination Survey, 1988-1994. Diabetes Care 28: 518-24.

2. King H, Aubert RE, Herman WH, 1998 Global burden of diabetes, 1995-2025. Prevalence, numerical estimates and projections. Diabetes Care 21: 1414-1431.

3. McCarty D, Zimmet PZ, Diabetes 1994-2010: Global estimates and projections. Melbourne, Australia, International Diabetes Institute 1994.

4. Nathan DM, 1993 Long term complications of diabetes mellitus. N Engl J Med 328: 1676-1685.

5. Clark CM Jr, Lee DA, 1995 Prevention and treatment of the complications of diabetes mellitus. N Engl J Med 332: 1210-1217.

6. Kuusisto J, Mykkanen L, Pyorala K, et al, 1994 NIDDM and its metabolic control predict coronary heart disease in elderly subjects. Diabetes 43: 960-967.

7. Rubin RJ, Altman WM, Mendelson DN, 1994 Healthcare expenditures for people with diabetes mellitus, 1992. J Clin Endocrinol Metab 78: 809A-809F.

8. Brown JB, Pedula KL, Bakst AW, 1999 The progressive cost of complications in type 2 diabetes mellitus. Arch Intern Med 159: 1873-1880.

9. Eastman RC, Silverman R, Harris M, et al, 1993 Lessening the burden of diabetes. Intervention strategies. Diabetes Care 16: 1095-1102.

10. Klein R, Klein BE, Moss SE, et al, 1994 Relationship of hyperglycemia to the long-term incidence and progression of diabetic retinopathy. Arch Intern Med 154: 21692178.

11. Gilbert RE, Tsalamandris C, Bach LA, et al, 1993 Longterm glycemic control and the rate of progression of early diabetic renal disease. Kidney Int 44: 855-859.

12. Haffner M, Stern M, Hazuda H, et al, 1990 Cardiovascular risk factors in confirmed prediabetic individuals. Does the clock for coronary heart disease start ticking before the onset of clinical diabetes? JAMA 263: 2893-2898.

13. Zimmet P, Alberti KGMM, 1997 The changing face of macrovascular disease in non-insulin dependent diabetes mellitus in different cultures: an epidemic in progress. Lancet 350: 1-4.

14. Gerich J, 1998 The genetic basis of type 2 diabetes mellitus: Impaired insulin secretion versus impaired insulin sensitivity. Endocr Rev 19: 491-503.

15. Dostou J, Gerich G, 2001 Pathogenesis of type 2 diabetes mellitus. Exp Clin Endocrinol Diabetes 109: 149-156.

16. Florez H, 1997 Steps toward the primary prevention of type II diabetes mellitus. Various epidemiological considerations. Invest Clin 38: 39-52.

17. Molbak AG, Christau B, Marner B, et al, 1994 Incidence of insulin-dependent diabetes mellitus in age groups over 30 years in Denmark. Diabet Med 11: 650-655.

18. Gerich J, 1997 Metabolic abnormalities in impaired glucose tolerance. Metabolism 46: 40-43.
19. Lilloja S, Mott DM, Spraul M, et al, 1993 Insulin resistance and insulin secretory dysfunction as precursors to non-insulin-dependent diabetes mellitus. Prospective study of Pima Indians. N Engl J Med 329: 1988-1992.

20. Chen KW, Boyko EJ, Bergstrom RW, et al, 1995 Earlier appearance of impaired insulin secretion than visceral adiposity in the pathogenesis of type 2 diabetes: 5 -year follow-up of initially nondiabetic Japanese-American men. Diabetes Care 18: 747-753.

21. Shaten BJ, Smith GD, Kuller LH, et al, 1993 Risk factors for the development of type 2 diabetes among men enrolled in the usual care group of the Multiple Risk Factor Intervention Trial. Diabetes Care 16: 1331-1339.

22. Wannamethee SG, Shaper AG, 1999 Weight change and duration of overweight and obesity in the incidence of type 2 diabetes. Diabetes Care 21: 350-359.

23. Kjos SL, Peters RK, Xiang A, et al, 1995 Predicting future diabetes in Latino women with gestational diabetes: Utility of early postpartum glucose tolerance testing. Diabetes 44: 586-591.

24. Pradhan AD, Manson JE, Rifai N, et al, 2001 C-reactive protein, interleukin 6 and risk of developing type 2 diabetes mellitus. JAMA 286: 327-334.

25. Solomon CG, Hu FB, Dunaif A, et al, 2001 Long or highly irregular menstrual cycles as a marker for risk of type 2 diabetes mellitus. JAMA 286: 2421-2426.

26. Forsen T, Eriksson J, Tuomilehto J, et al, 2000 The fetal and childhood growth of persons who develop type 2 diabetes. Ann Intern Med 133: 176-182.

27. Manson JE, Ajani UA, Liu S, et al, 2000 A prospective study of cigarette smoking and the incidence of diabetes mellitus among US male physicians. Am J Med 109: 538542.

28. Kadowski T, Miyaki Y, Hagura R, et al, 1984 Risk factors for worsening to diabetes in subjects with impaired glucose tolerance. Diabetologia 26: 44-49.

29. Vegt F, Dekker JM, Jager A, et al, 2001 Relation of impaired fasting and postload glucose with incident type 2 diabetes in a Dutch population: the Hoorn Study. JAMA 285: 2109-2113.

30. Report of the Expert Committee on the diagnosis and Classification of Diabetes Mellitus, 1997. Diabetes Care 20: 1183-1197.

31. Edelstein SL, Knowler WC, Bain RP, et al, 1997 Predictors of progression from impaired glucose tolerance to NIDDM: an analysis of six prospective studies. Diabetes 46: 701-710.

32. McDonald GW, Fisher GF, Burnham C, 1965 Reproducibility of the oral glucose tolerance test. Diabetes 14: 473.

33. Eriksson J, Franssila-Kallunki A, Ekstrand A, et al, 1989 Early metabolic defects in persons at increased risk for non-insulin-dependent diabetes mellitus. N Engl J Med 321: 337-343.

34. Stern MP, Williams K, Haffner SM, 2002 Identification of persons at high risk for type 2 diabetes mellitus: do we need the oral glucose tolerance test? Ann Intern Med 136: 575-581.

35. Santiago JV, Davis JE, Fisher F, 1978 Hemoglobin A 
levels in a diabetes detection program. J Clin Endocrinol Metab 47: 578-580.

36. Gabay KH, Sosenko JM, Banuchi GA, et al, 1979 Glycosylated hemoglobins: increased glycosylation of hemoglobin A in diabetic patients. Diabetes 28: 337-340.

37. Little RR, England JD, Wiedmyer HM, et al, 1994 Glycated haemoglobin predicts progression to diabetes mellitus in Pima Indians with impaired glucose tolerance. Diabetologia 37: 252-256.

38. American Diabetes Association and National Institutes of Diabetes, Digestive and Kidney Diseases, 2002 The prevention or delay of type 2 diabetes. Position Statement. Diabetes Care 25: 742-749.

39. Nijpels G, Popp-Snijders C, Costense PJ, et al, 1996 Fasting proinsulin and 2-h post-load glucose levels predict the conversion to NIDDM in subjects with impaired glucose tolerance: the Hoorn Study. Diabetologia 39: 113-118.

40. Sandhu MS, Heald AH, Gibson JM, et al, 2002 Circulating concentrations of insulin-like growth factor-I and development of glucose intolerance: a prospective observational study. Lancet 359: 1740-1745.

41. National Institutes of Health. National Heart, Lung and Blood Institute. 1998 Clinical guidelines on the identification, evaluation and treatment of overweight and obesity in adults: the evidence report. Obes Res 6: 515.

42. Harris MI, 1989 Impaired glucose tolerance in the U.S. population. Diabetes Care 12: 464-474.

43. DeFronzo RA, Ferrannini E, 1991 Insulin resistance. A multifaceted syndrome responsible for NIDDM, obesity, hypertension, dyslipidemia and atherosclerotic cardiovascular disease. Diabetes Care 14: 173-194.

44. Chan JM, Rimm EB, Colditz GA, et al, 1994 Obesity, fat distribution and weight gain as risk factors for clinical diabetes in men. Diabetes Care 17: 961-969.

45. Abate N, Garg A, Peshock RM, et al, 1995 Relationship of generalized and regional adiposity to insulin sensitivity in man. J Clin Invest 96: 88-98.

46. Van Dam RM, Rimm EB, Willett WC, et al, 2002 Dietary patterns and risk for type 2 diabetes mellitus in U.S. men. Ann Intern Med 136: 201-209.

47. Pereira MA, Jacobs DR Jr, Van Jorn L, et al, 2002 Dairy consumption, Obesity and the Insulin Resistance Syndrome in Young Adults: The CARDIA Study. JAMA 287: 2081-2089.

48. Phillips DI, Barker DJ, Hales CN, et al, 1994 Thinness at birth and insulin resistance in adult life. Diabetologia 37: $150-154$

49. Phillips DI, Barker DJ, Fall CH, et al, 1998 Elevated plasma cortisol concentrations: A link between low birth weight and the insulin resistance syndrome. J Clin Endocrinol Metabol 83: 757-760.

50. Han TS, Sattar N, Williams K, et al, 2002 Prospective study of C-Reactive Protein in relation to the development of diabetes and metabolic syndrome in the Mexico City Diabetes Study. Diabetes Care 25: 2016-2021.

51. Rimm EB, Manson JE, Stampfer MJ, et al, 1993 Cigarette smoking and the risk of diabetes in women. Am J Public Health 83: 211-214.
52. Rimm EB, Chan J, Stampfer MJ, et al, 1995 Prospective study of cigarette smoking, alcohol use and the risk of diabetes in men. BMJ 310: 555-559.

53. Uchimoto S, Tsumura K, Hayashi T, et al, 1999 Impact of cigarette smoking on the incidence of type 2 diabetes mellitus in middle-aged Japanese men: the Osaka Health Survey. Diabet Med 16: 951-955.

54. Kawakami N, Takatsuka N, Shimizu H, et al, 1997 Effects of smoking on the incidence of non-insulin-dependent diabetes mellitus: replication and extension in a Japanese cohort of male employees. Am J Epidemiol 145: 103-109.

55. Feskens EJ, Kromhout D, 1989 Cardiovascular risk factors and the 25-year incidence of diabetes mellitus in middle-aged men. The Zutphen Study. Am J Epidemiol 130: 1101-1108.

56. Haire-Joshu D, Glasgow RE, Tibbs TL, 1999 Smoking and diabetes. Diabetes Care 22: 1887-1898.

57. Janson L, Berntrop K, Hanson M, et al, 1983 Glucose tolerance and smoking: a population study of oral and intravenous glucose tolerance tests in middle-aged men. Diabetologia 25: 86-88.

58. Frati AC, Iniestra F, Ariza CR, 1996 Acute effect of cigarette smoking on glucose tolerance and other cardiovascular risk factors. Diabetes Care 19: 112-118.

59. Shimokata H, Muller DC, Andres R, 1989 Studies in the distribution of body fat. III. Effects of cigarette smoking. JAMA 261: 1169-1173.

60. Pendergrass M, Fazioni E, DeFronzo RA, 1995 Non-insulin-dependent diabetes mellitus and gestational diabetes mellitus: Same disease, another name? Diabetes Reviews 3: 566-583.

61. Buchanan TA, Catalano PM, 1995 The pathogenesis of GDM: implications for diabetes after pregnancy. Diabetes Reviews 3: 584-601.

62. Tamas G, Kerenyi Z, 2001 Gestational diabetes: current aspects on pathogenesis and treatment. Exp Clin Endocrinol Diabetes 109: 400-411.

63. Bennett PH, Epidemiology of diabetes mellitus. In: Ellenberg and Rifkin's Diabetes Mellitus, Rifkin H, Porter D, Jr. (eds), Elsevier, New York 1990; p. 363.

64. Klein BE, Klein R, Moss SE, et al, 1996 Parental history of diabetes in a population-based study. Diabetes Care 19: 827.

65. Winter W, Nakamura M, House D, 1999 Monogenic diabetes mellitus in youth. The MODY syndromes. Endocrinol Metab Clin North Am 28: 765-785.

66. Kadowaki T, Kadowaki H, Mori Y, et al, 1994 A subtype of diabetes mellitus associated with a mutation of mitochondrial DNA. N Engl J Med 330: 962-968.

67. Horikawa Y, Oda N, Cox NJ, et al, 2000 Genetic variation in the gene encoding calpain-10 is associated with type 2 diabetes mellitus. Nat Genet 26: 163-175.

68. Knowler W, Pettitt D, Saad M, et al, 1990 Diabetes mellitus in the Pima Indians: incidence, risk factors and pathogenesis. Diabetes Metab Rev 6: 1-27.

69. Newman B, Selby J, King M, et al, 1987 Concordance in type II (non-insulin-dependent) diabetes mellitus in male 
twins. Diabetologia 30: 763-768.

70. Devlin JT, 1992 Effects of exercise on insulin sensitivity in humans. Diabetes Care 15: 1690-1693.

71. Helmrich SP, Ragland DR, Leung RW, et al, 1991 Physical activity and reduced occurrence of non-insulin-dependent diabetes mellitus. N Engl J Med 325: 147-152.

72. Eriksson KF, Lindgerde F, 1991 Prevention of type 2 (noninsulin-dependent) diabetes mellitus by diet and physical exercise. The 6-year Malmo feasibility study. Diabetologia 34: 891-898.

73. Pan XR, Li GW, Hu YH, et al, 1997 Effects of diet and exercise in preventing NIDDM in people with impaired glucose tolerance. The Da Qing IGT and Diabetes Study. Diabetes Care 20: 537-544.

74. Tuomilehto J, Lindstrom J, Ericsson JG, et al, for the Finnish Diabetes Prevention Study Group. 2001 Prevention of type 2 diabetes mellitus by changes in lifestyle among subjects with impaired glucose tolerance. N Engl J Med 344: 1343-1350.

75. Knowler WC, Barrett-Connor E, Fowler S, et al, for the Diabetes Prevention Program Research Group. 2002 Reduction in the incidence of type 2 diabetes with lifestyle intervention or metformin. N Engl J Med 346: 393403.

76. Hu FB, Manson JE, Stampfer MJ, et al, 2001 Diet, lifestyle, and the risk of type 2 diabetes mellitus in women. $\mathrm{N}$ Engl J Med 345: 790-797.

77. Liao D, Asberry PJ, Shofer JB, et al, 2002 Improvement of BMI, body composition and body fat distribution with lifestyle modification in Japanese Americans with impaired glucose tolerance. Diabetes Care 25: 1504-1510.

78. Long SD, O’Brien K, McDonald KG, et al, 1994 Weight loss in severely obese subjects prevents the progression of impaired glucose tolerance to type II diabetes. A longitudinal intervention study. Diabetes Care 17: 372-375.

79. Wannamethee SG, Shaper AG, Perry IJ, 2001 Smoking as a modifiable risk factor for type 2 diabetes in middleaged men. Diabetes Care 24: 1590-1595.

80. Bailey CJ, Turner RC, 1996 Metformin. N Engl J Med 334: 574-579.

81. Stumvoll M, Nurjhan N, Perriello G, et al, 1995 Metabolic effects of metformin in non-insulin-dependent diabetes mellitus. N Engl J Med 333: 550-554.

82. Dunn CJ, Peters DH, 1995 Metformin. A review of its pharmacological properties and therapeutic use in noninsulin-dependent diabetes mellitus. Drugs 49: 721-749.

83. Lee A, Morley JE, 1998 Metformin decreases food consumption and induces weight loss in subjects with obesity with type 2 non-insulin-dependent diabetes. Obes Res 6: 47-53.

84. Chiasson J-L, Josse RG, Gomis R, et al, 2002 Acarbose for prevention of type 2 diabetes mellitus: the STOP-NIDDM randomized trial. Lancet 359: 2072-2077.

85. Chiasson J-L, Josse RG, Leiter LA, et al, 1996 The effects of acarbose on insulin sensitivity in subjects with impaired glucose tolerance. Diabetes Care 19: 1191-1194.

86. Buchanan TA, Xiang AH, Peters RK, et al, 2002 Prevention of pancreatic beta-cell function and prevention of type 2 diabetes by pharmacological treatment of insulin resistance in high risk Hispanic women. Diabetes 51: 279627803.

87. Sjostrom L, Torgerson JS, Hauptman J, et al, XENDOS (XENical in the prevention of Diabetes in Obese Subjects): a landmark study. 9th International Congress on Obesity. August 24-29, 2002; Sao Paolo, Brazil.

88. Yusuf S, Sleight P, Pogue J, et al, 2000 Effects of an angiotensin-converting-enzyme inhibitor, ramipril, on cardiovascular events in high-risk patients. The Heart Outcomes Prevention Evaluation Study Investigators. N Engl J Med 342: 145-153.

89. Dahlof B, Devereux RB, Kjeldsen SE, et al, 2002 Cardiovascular morbidity and mortality in the Losartan Intervention for Endpoint reduction in hypertension study (LIFE): a randomized trial against atenolol. Lancet 359: 995-999.

90. Alkharouf J, Nalinkumari K, Corry D, et al, 1993 Longterm effects of the angiotensin converting enzyme inhibitor captopril on metabolic control in non-insulin-dependent diabetes mellitus. Am J Hypertens 6: 337-343.

91. Keen H, Jarrett RJ, McCartney P, 1982 The ten-year follow-up of the Bedford survey (1962-1972): glucose tolerance and diabetes. Diabetologia 22: 73-78.

92. Sartor G, Schersten B, Carlstrom S, et al, 1980 Ten-year follow-up of subjects with impaired glucose tolerance: prevention of diabetes by tolbutamide and diet regulation. Diabetes 29: 41-49.

93. Stowers J, 1973 Treatment of chemical diabetes with chlorpropamide and the associated mortality. Adv Metab Dis 2: $549-555$.

94. Zimmet P, 2000 Globalization, coca-colonization and the chronic disease epidemic: can the Doomsday scenario be averted? J Intern Med 247: 301-310.

95. Narayan KMV, Bowman BA, Engelgau ME, 2001 Prevention of type 2 diabetes. BMJ 323: 63-64.

96. Wing RR, Venditti E, Jakicic JM, et al, 1998 Lifestyle intervention in overweight individuals with a family history of diabetes. Diabetes Care 21: 350-359.

97. Knowler WC, Narayan KMV, Hanson RL, et al, 1995 Preventing non-insulin-dependent diabetes mellitus. Diabetes 44: 483-488.

98. Narayan KMV, Imperatore G, Benjamin SM, et al, 2002 Targeting people with pre-diabetes. BMJ 325: 403-403. 